\title{
Raízes recentes do Mercosul
}

\author{
Maria Izabel Mallmann ${ }^{1}$
}

A história recente da América Latina mostra que muitas têm sido as iniciativas promissoras de cooperação que, apesar das crises recorrentes, têm contribuído para alterar sensivelmente a trajetória das relações regionais. Prova disso pode ser observada nas experiências de cooperação econômica e comercial que, em muitos aspectos, inovam em relação a exemplos anteriores.

Talvez o balanço desses acontecimentos, concentrados nas últimas décadas, seja tanto mais positivo quanto mais se compare com a precariedade dos resultados obtidos ao longo dos quase duzentos anos de independência. Isto porque as prioridades de política externa dos governos latino-americanos revelam que, historicamente, os mesmos inclinaram-se mais para os ganhos menores e menos arriscados de uma parceria com o centro do sistema do que para a aventura de construir um projeto regional comum, embora tenham existido heróicos esforços neste sentido. Essa opção, condicionada ou não por fatores estruturais, moldou a política externa dos países latino-americanos ao longo do período pós-independência. Apenas recentemente essa situação tem mostrado sinais de mudança. Alterações no contexto internacional, claramente perceptíveis desde meados da década de 60, introduziram fatores que subverteram a ordem bipolar e desarticularam das relações regionais de poder, habilmente estruturadas a partir do segundo pós-guerra.

Na década de 1980, acontecimentos regionais sobrepuseram-se às tendências mundiais em curso, agravando as já bastante deterioradas relações entre os países

${ }^{1}$ Doutora, em Ciências Políticas pela Sorbonne, Paris III, professora adjunta da Pontifícia Universidade Católica do Rio Grande do Sul - PUCRS. 
latino-americanos e os Estados Unidos e contribuindo para a soma de esforços por parte de governos latino-americanos na busca de soluções para os problemas regionais. A chamada década perdida, em alusão ao atraso econômico ocorrido na região naqueles anos, foi, talvez por isso mesmo, uma década de significativos ganhos políticos. Os desdobramentos regionais da crise econômico-financeira mundial, somados às dificuldades comerciais das economias latino-americanas e, sobretudo, à indiferença dos organismos e governos centrais ao quadro de crise que se desenhou, contribuíram para a percepção, por parte dos governos da região de que uma solução alternativa deveria ser encontrada. A natureza dessa solução, por sua vez, esteve condicionada regionalmente tanto por fatores de ordem econômico-financeira, quanto político-estratégica.

Levando-se em conta o passado, avalia-se que a aproximação entre os países latino-americanos, havida nas duas últimas décadas do século XX, representa uma importante mudança de orientação no que diz respeito às relações regionais da América Latina. Considera-se que os acontecimentos dos anos 1980, são, nesse sentido, extremamente relevantes para compreender essa mudança e contextualizar as origens recentes do que se considera regionalmente mais importante em termos de integração econômica dos últimos tempos, o Mercosul.

\section{Desafios}

Os grandes desafios diante dos quais encontravam-se os países latino-americanos no limiar dos anos 80 decorriam da necessidade de superar as situações críticas de endividamento externo e de crise comercial e política, agravadas pelo esgotamento do modelo de desenvolvimento econômico e pela falta de legitimidade dos governos.

A situação de endividamento externo das economias latino-americanas foi altamente danosa para a região. Em 1982, para cada aumento de um ponto percentual na taxa de juros, aumentava em US\$ 2.500 milhões o gasto anual em serviços da dívida regional. Naquele ano, a dívida externa latino-americana totalizava mais da metade do Produto Interno Bruto (PIB) regional e era três vezes maior do que as exportações anuais da América Latina (Navarrete, 1987).

A dívida externa das principais economias latino-americanas atingira tal magnitude no início da década de 1980 que teria comprometido o sistema bancário internacional, caso a solução para o problema se inclinasse a favor dos devedores. Em 1982, o comprometimento líquido dos cem maiores bancos do mundo era igual a 125\% dos capitais acionários; em 1987 esse percentual baixou para 75\% (Tom 
Camargo, Gazeta Mercantil, 20/1/1989, p 1, 2). No entanto, essa recuperação do sistema bancário não resultou em flexibilizações consideráveis nas negociações com os devedores. No decorrer dos anos 80 , apenas pequenas mudanças foram introduzidas nas regras do sistema financeiro internacional, como as ocorridas, por exemplo, no período de negociações 1984/5 (Cepal, 1986, p. 60-1).

A opção por sustentar os compromissos externos e a necessidade de gerar divisas daí decorrente levaram os governos latino-americanos a adotar políticas internas recessivas. Tais políticas geraram graves conseqüências sócio-econômicas, como a desindustrialização e o desemprego, a miséria e a violência individual e coletiva, ocasionando instabilidade social e política.

No plano comercial, as economias centrais entretinham entre si o mais importante das transações financeiras e comerciais, restringindo as fontes comerciais de captação de divisas pelos países periféricos (Arifin, Graz, 1993). Ademais, a retomada da integração européia em meados dos anos 80 e a adesão norte-americana ao regionalismo, via Nafta, prometiam maiores dificuldades comerciais para as economias excluídas de tais blocos. Essa situação fomentava a idéia de que algo deveria ser feito para evitar a total marginalização das economias latino-americanas. Não havia, no entanto, clareza sobre que rumos tomar.

Além dos desafios decorrentes dessa situação econômico-financeira calamitosa, os novos chegados ao poder nos anos 80 tiveram que tomar certas decisões condicionadas por fatores não menos desafiadores. A opção pelo modelo de desenvolvimento protegido que marcara os rumos da economia regional no segundo pós guerra mostrava-se inviável face aos desafios de um contexto econômico mundial crescentemente aberto e competitivo. Simultaneamente, esgotava-se o ciclo de autoritarismos e a legitimidade dos novos governos não apenas os liberava para tomar decisões descomprometidas com o passado recente, como, em certo sentido, compelia-os a fazê-lo. Porém, o ritmo acelerado das mudanças nos fluxos econômicos não era acompanhado pelas mudanças políticas, de modo que não se apresentavam projetos políticos capazes de constituir-se, no curto prazo, em alternativas viáveis à orientação liberal da economia. Essa alternativa foi sendo construída gradualmente, no ritmo politicamente possível das respostas aos desafios. Nesse contexto, foram revistos os termos de certas alianças externas e, sobretudo, abertas novas possibilidades de alianças, menos ambiciosas e mais pragmáticas.

A explosão das contas externas do México, em 1982, colocou o sistema financeiro internacional na defensiva e alertou os devedores latino-americanos para a necessidade de encontrarem soluções não convencionais para a crise da dívida externa. Na busca de tais soluções, os governos latino-americanos e caribenhos 
divulgaram a declaração de Quito, por ocasião da Conferência Econômica LatinoAmericana, realizada em Quito, em janeiro de 1984. A Declaração continha uma apreciação da situação econômico-financeira regional e revelava a disposição dos participantes de impulsionar as instituições regionais com vistas a tratarem da crise da dívida externa latino-americana (Declaración de Quito, 1984). Essa disposição teve maiores desdobramentos práticos na reunião entre representantes de governos latino-americanos ocorrida em junho de 1984. Naquela ocasião, os chanceleres e ministros da economia da Argentina, Brasil, Bolívia, Chile, Colômbia, Equador, México, Peru, República Dominicana, Uruguai e Venezuela, reunidos em Cartagena, Colômbia, para discutirem a situação econômico-financeira internacional e especialmente o endividamento externo da América Latina, criaram o Consenso de Cartagena como instância permanente de debates sobre essas questões. O endividamento, segundo eles, evidenciaria um quadro de corresponsabilidade de credores e devedores que exigia tratamento político por parte dos credores (Consenso de Cartagena, jul.-set., 1984).

No decorrer dos anos 80, apenas pequenas flexibilizações foram introduzidas nas regras do sistema financeiro internacional, como as ocorridas, por exemplo, no período de negociações 1984/5. A partir desse período, os bancos privados abriram mão de manter, em todos os casos, a sua insistência em condicionar o acordo de reprogramação a um projeto de ajuste previamente firmado com o FMI. Outras alterações introduzidas na rodada de negociações de 1984/5 foram o aumento dos montantes de amortizações reprogramadas, a reprogramação das amortizações a períodos mais longos e a introdução de condições mais favoráveis em termos de prazos, taxas de juros e comissões. Por outro lado, em contrapartida a essas concessões, os bancos reduziram os créditos adicionais a montantes inferiores aos concedidos nos períodos de negociação anteriores e menores que o total dos juros pagos pelos devedores (Cepal, 1986: 60-1). Em síntese, pode-se dizer que os devedores latino-americanos esgotaram as possibilidades de pressão diplomática e obtiveram escasso retorno de parte dos credores.

Embora as gestões da crise da dívida externa levadas a termo no âmbito do Consenso de Cartagena não tenham obtido resultados satisfatórios do ponto de vista propriamente financeiro, reforçaram a tendência de coordenação política entre os governos latino-americanos em torno de temas comuns. Atitudes nesse sentido foram favorecidas pelos desdobramentos políticos de acontecimentos como a guerra das Malvinas (1982) ${ }^{2}$ e a crise política centro-americana, que chamaram a

${ }^{2}$ Em 2 de abril de 1982 tropas argentinas invadiram as Ilhas Malvinas pretendendo retomar a soberania sobre as mesmas, desde 1833 sob jurisdição britânica. No mesmo dia, a Grã-Bretanha 
atenção do mundo e, especialmente, dos latino-americanos para a precariedade da aliança regional com os Estados Unidos, e dispuseram muitos governos a repensála e a buscar soluções próprias para seus problemas.

\section{Contexto político}

A chamada década economicamente perdida reuniu condições políticas, tanto internas quanto externas, que favoreceriam a adoção de medidas externas relativamente arrojadas para os padrões latino-americanos. O esgotamento dos regimes militares introduziu na cena regional lideranças menos comprometidas com a continuidade de certas políticas e bastante pressionadas para romper com elas. Simultaneamente, no plano regional, alguns acontecimentos precipitaram a crise das relações entre os países latino-americanos e os Estados Unidos, estes bastante envolvidos com seus problemas domésticos. Acredita-se que esse conjunto de fatores criaram as condições políticas para a adoção de estratégias de política externa que tiveram seus efeitos mais perceptíveis nos anos 90 .

A guerra das Malvinas consistiu numa espécie de gota d'água que liberou formalmente os governos latino-americanos do alinhamento aos Estados Unidos.

$\mathrm{Na}$ fase inicial do conflito, os Estados Unidos aparentavam uma postura neutra. Segundo Henry Gatto, porta-voz do Pentágono, os Estados Unidos não dariam "ajuda de qualquer tipo a ninguém" e adotariam uma postura "totalmente eqüidistante" (Reimann, 1983: 54-5). Não incompatibilizar-se seriamente com qualquer dos aliados parecia ser a opção dos Estados Unidos quando o conflito ainda não atingira maiores proporções. Contudo, a censura norte-americana à atuação argentina esteve manifesta desde o dia da invasão das ilhas. Naquele dia, o Departamento de Estado norte-americano expediu uma nota através da qual conclamava o governo argentino a "cessar imediatamente as hostilidades" e a retirar suas forças militares das ilhas (Reimann, 1983, p. 52).

No decorrer de suas atividades de mediação, iniciadas no quinto dia de conflito, os Estados Unidos foram tornando cada vez mais explícito seu apoio à causa britânica, até o ponto de assumi-lo plenamente, afastando-se da mediação e sustentando irrestritamente a posição britânica, ${ }^{3}$ o que aconteceu na terceira semana

recorreu ao Conselho de Segurança da ONU que, a 3 de abril, aprovou a Resolução 502 segundo a qual as tropas argentinas deveriam abandonar as Ilhas. Em 5 de abril, Margaret Thatcher enviou uma frota de guerra britânica para o Atlântico Sul, e, no dia seguinte, Alexander Haig, Secretário de Estado norte-americano, iniciou os trabalhos de mediação do conflito.

${ }^{3}$ Cronologia do conflito das Malvinas ver em Reimann, Elizabeth, 1983. 
de conflito quando o então Secretário de Estado norte-americano, Alexander Haig, advertiu que os Estados Unidos apoiariam o Reino Unido, com quem possuíam acordos para atuação conjunta em casos de guerra. De fato, após o abandono da mediação, os Estados Unidos apenas intensificaram o apoio que vinham dando ao Reino Unido em termos logísticos, através de sua base militar na ilha de Ascensão, no Atlântico Sul (Reimann, 1983: 60).

Embora os países latino-americanos não se tenham posicionado unanimemente a favor da Argentina, o que teria representado apoio incondicional a soluções de força e também a um dos mais violentos regimes militares da América-latina, o episódio rendeu a revisão crítica das alianças estratégicas dos países latino-americanos que, naquele contexto, consistiu em mais um fator a favor da busca de caminhos alternativos.

Outro acontecimento relevante nesse sentido, foi o conflito político centroamericano. Este, abriu espaço para que surgisse uma diplomacia fundamentada na coordenação de posições em torno da obtenção da paz na América Central, o que deu curso a uma promissora via de coordenação de políticas.

A queda da ditadura nicaragüense de Anastasio Somoza, ocorrida em julho de 1979, foi a culminância de um processo político que teve greves, insurreições populares, luta armada e a instauração de um governo provisório pela Frente Sandinista, posteriormente vitoriosa nas eleições gerais. No entanto, os acontecimentos naquele país seguiram um curso contrário às expectativas do governo norte-americano, o qual, desejoso de reabilitar seu prestígio interno, pretendia manter sob seu controle a transição para a democracia na Nicarágua, mesmo que isso implicasse o envio de tropas à Nicarágua (Díaz-Callejas, 1985, p. 60-1). Nesses termos, os Estados Unidos passaram a defender propostas intervencionistas e adotaram decisões nesse sentido, condicionando a ajuda econômica ao alinhamento político, financiando e treinando grupos armados de oposição e fortalecendo governos autoritários locais de modo a reverter a tendência revolucionária (García Peña, 1985).

Para gestionar a paz na América Central, em oposição à via de pacificação pela força proposta pelos Estados Unidos, foi criado o Grupo de Contadora, em 1983, pelo México, Colômbia, Panamá e Venezuela. Em 1985, o Grupo recebeu reforço das jovens democracias da Argentina, Brasil, Peru e Uruguai, o que passou a ser chamado de Grupo de Apoio à Contadora. Em 1987, o conjunto dos países envolvidos com a pacificação da América Central passou a ser referido como Grupo dos Oito que, nos anos 90, viria a ser conhecido como Grupo do Rio, cuja agenda passou a incluir temas latino-americanos em geral. 
A gestão pela paz na América Central levada a termo pelo Grupo de Contadora e seus apoiadores fundamentou-se na interpretação do princípio da não intervenção, defendendo a mediação diplomática do conflito. Embora não se possa dizer que o Grupo obteve total sucesso em seu empreendimento, ${ }^{4}$ no que diz respeito ao objetivo deste artigo, qual seja, o de recuperar, naquelas experiências, os indícios de uma cooperação mais estreita entre países latino-americanos, Contadora teve um papel relevante. Aquela experiência mostrou à América Latina e ao mundo ser possível conduzir negociações conjuntas mesmo em situações delicadas e inusitadas que envolvam a sustentação de posições diferentes e mesmo opostas às defendidas pelos Estados Unidos, como o que foi o tema original de Contadora.

As experiências diplomática em torno da questão centro-americana e da guerra das Malvinas aproximaram os países latino-americanos, a maioria recém saída de regimes autoritários. Estima-se que tais experiências facilitaram a busca de soluções compartidas para os desafios maiores, de natureza econômica, uma vez que favoreceram a aproximação latino-americana.

Foi no âmbito de tais acontecimentos que Argentina e Brasil iniciaram um histórico processo de aproximação que viria, nos anos 90, a constituir o Mercosul. ${ }^{5}$ As iniciativas tomadas pelos governos de Raúl Alfonsín e José Sarney no sentido de superar as rivalidades mútuas e preparar o caminho para trocas mais estreitas não esteve, portanto, isolado dos acontecimentos dos anos 80 que favoreceram a reestruturação das relações regionais. A importância histórica dessa experiência supera em muito seus modestos resultados absolutos. O grande mérito do Mercosul decorre do seu significado político, ou seja, de ser fruto de uma decisão tomada com o intuito de criar as condições necessárias para a busca conjunta de soluções para os problemas regionais comuns. O Mercosul é, portanto, uma iniciativa de integração econômica que repousa em atos de vontade política que superam outros exemplos históricos por fundamentar-se em razões quase que exclusivamente políticas (Gaiero, Romero, 1996). Basta lembrar que a singeleza dos fluxos materiais entre as economias envolvidas jamais justificaria tamanho esforço diplomático. Nesse sentido, o Mercosul representa a vitória de uma visão estratégica e prospectiva, viabilizada num momento de reestruturação das relações regionais. Arias.

${ }^{4}$ As derradeiras gestões pela paz foram conduzidas pelo presidente costarriquenho Oscar

${ }_{5}^{5}$ Deixa-se de tratar em detalhe o surgimento do Mercosul uma vez que essa parte foi muito bem desenvolvida no artigo de Franklin Trein publicado neste número. 


\section{Considerações finais}

Como já foi mencionado, fundamental para a compreensão dos acontecimentos desse período, foi a onda redemocratizante que tomou conta da América Latina e legitimou a adoção de estratégias políticas opostas ou, pelo menos, diferentes das até então implementadas. Constrangidos pela crise econômica, política e social interna e pela hostilidade internacional, os novos chegados ao poder pela via democrática viram-se na obrigatoriedade e, em certa medida, encontraram condições propícias para ousarem em termos de invenção do futuro. Infelizmente, as vicissitudes do processo e, sobretudo, as nem sempre mais acertadas escolhas de partida, não têm, contudo, contribuído para coroar esse empreendimento de pleno êxito. No entanto, a aproximação entre os países latino-americanos, por problemática que possa estar sendo, reveste-se de uma importância histórica ímpar se for considerado que esse movimento data das duas últimas décadas dos quase dois séculos de vida independente desses países.

Portanto, as condições políticas favoráveis, tanto internas quanto externas possibilitaram a busca de soluções inovadoras face aos desafios comuns que se apresentaram à América Latina nos anos 80.

O alinhamento político latino-americano aos Estados Unidos no segundo pósguerra restringira as já reduzidas possibilidades de coordenação de políticas entre os governos latino-americanos. Até o final dos anos 70, os problemas políticos regionais não mereciam qualquer ação coordenada por parte dos governos latinoamericanos que configurasse alguma coesão em torno de posicionamentos comuns. Por várias vezes, após a Segunda Guerra, crises políticas nacionais na América Latina tornaram-se questões regionais devido à ingerência norte-americana na política interna de países latino-americanos. São exemplos históricos dessa situação as intervenções norte-americanas na Guatemala, em 1954, e na República Dominicana, em 1965. Em nenhum dos casos os Estados Unidos enfrentaram oposição organizada dos governos latino-americanos às suas práticas intervencionistas. Ao contrário disso, obtiveram a adesão dos mesmos a elas (Van Klaveren, 1984: 519).

Nos anos 80, como foi visto, as ações conjuntas de vários governos latinoamericanos em torno de importantes questões regionais alteraram o perfil da cooperação latino-americana, e, acredita-se, propiciaram a busca de soluções conjuntas às dificuldades comuns também no plano econômico, exemplo disso, têm sido as experiências do Mercosul, da Comunidade Andina e das negociações para a construção da Área de livre comércio sul-americana (Alcsa), bem como das negociações no âmbito da Área de livre comércio da América (Alca). 


\section{Bibliografia}

ARIFIN, Yohan, GRAZ, Jean-Cristophe. Le mercantilisme transnacional à l'oeuvre dans le processus de régionalisation commerciale. Le Trimestre du Monde, $\mathrm{n}$. 22, 1993, $2^{\circ}$ trimestre, p. 75-97.

CAMARGO, Tom. Sugerida uma redução da dívida. Gazeta Mercantil, São Paulo, 20/1/1989, p. 1-2.

Cepal, Estudio Económico de América Latina y el Caribe. Anuário 1985. Santiago, $1986,672 \mathrm{p}$.

CONSENSO DE CARTAGENA. Endeudamento externo de América Latina; lineamientos generales de políticas de reestructuración y financiamiento. Contribuciones, Buenos Aires, n. 3, jul.-set., 1984, p. 113-118.

GAIERO, José Luis, ROMERO, María del Huerto. Integración regional en América: integración de hecho (Nafta) versus construcción del poder político (Mercosur). In: LAREDO, Iris (org.). Estado, Mercado y Sociedad en el Mercosur. Pautas para su viabilización. Vol. II. Rosario, Argentina: Ed. El Puente, 1996, p. 59-81.

García Peña, Rodrigo Pardo, CEPEDA-ULLOA, Fernando (orgs.). Contadora; desafio a la diplomacia tradicional. Bogotá, Oveja Negra, 1985, 187 p.

Reimann, Elisabeth. Las Malvinas; traición made in USA. México, El Caballito, $1983,142 \mathrm{p}$.

Van Klaveren, Alberto. Las nuevas formas de concertación politica en América Latina. Estudios Internacionales, Santiago, v. 17, n. 68, 1984, p. 514-536. 
